\section{Aconselhamento na prevenção do HIV: olhar dos usuários de um centro de testagem}

\author{
Counseling for HIV prevention: the view of users at \\ a testing center
}

\author{
1 Universidade Federal de \\ Minas Gerais, Belo Horizonte, \\ Brasil, \\ 2 Escola Nacional de Saúde \\ Pública Sergio Arouca, \\ Fundação Oswaldo Cruz, Rio \\ de Janeiro, Brasil. \\ 3 Instituto Albam, Belo \\ Horizonte, Brasil. \\ Correspondência \\ V. Souza \\ Universidade Federal de \\ Minas Gerais. \\ Av. Alfredo Balena 190, sala \\ 414, Belo Horizonte, $M G$ \\ 30130-100, Brasil. \\ vaniaxsouza@yahoo.com.br
}

\section{Abstract}

This article analyzes the relevance ascribed to counseling for HIV prevention by users of a testing service. The study's main theoretical references were the democratization of discourse as proposed by Fairclough and the disciplinary power and confessional techniques analyzed by Foucault. The research was done from November 2005 to March 2006 at an HIV testing and counseling center in Minas Gerais State, Brazil. Thirty-two individuals participated in the study. Techniques included in-depth interviews and an adaptation of the content analysis method, with emphasis on thematic modality. The interpretation of counseling as a "necessary evil" revealed an ambivalent approach (both democratic and coercive), but this ambiguity did not appear problematic. The difficulty lay in constructing models for interaction that prioritized symmetry in the counseling relationship and focused on users' participation as key protagonists in HIV prevention.

Counseling; Acquired Immunodeficiency Syndrome; Health Education
Vânia de Souza 1,2

Dina Czeresnia 2

Cláudia Natividade 3

\section{Introdução}

Estudos nacionais e internacionais apontam o aconselhamento como uma prática decisiva na redução de situações de risco de exposição ao HIV, ao permitir uma relação direta e personalizada com os usuários do serviço 1,2,3,4,5,6. No Brasil, a primeira experiência oficial de orientação sobre modos de prevenção do HIV foi em 1988 com a implantação do primeiro Centro de Orientação e Apoio Sorológico (COAS). Em 1997 houve a consolidação da prática de aconselhamento e a mudança do nome COAS para Centro de Testagem e Aconselhamento (CTA). Atualmente, o aconselhamento é uma das prioridades do Programa Nacional de Doenças Sexualmente Transmissíveis e AIDS (PN-DST/AIDS) que tem como meta a incorporação dessa prática, nas atividades assistenciais já existentes nos serviços de saúde 2,7 .

Essa modalidade de assistência é fundamentada em três componentes: apoio emocional; apoio educativo e troca de informações; avaliação de riscos e elaboração de um plano de redução desses riscos, baseado nas necessidades, circunstâncias e habilidades do usuário ${ }^{2}$. O aconselhamento, portanto, é uma prática com considerável complexidade, fundamentada em um discurso que propõe mudanças na atitude dos sujeitos e que ao mesmo tempo busca respeitar suas características e expectativas pessoais $3,4,6,8,9$. 
Para Fairclough 10, o discurso do aconselhamento faz parte de um contexto de mudanças na interação entre profissionais e seus clientes, ao buscar estabelecer uma linguagem que tende para a informalidade e a conversação. $\mathrm{O}$ aconselhamento se configura como espaço de troca constituída por um modo de falar com as pessoas sobre si mesmas e seus problemas de forma aparentemente não-diretiva e não-avaliativa. $\mathrm{Na}$ visão do autor, o aconselhamento é uma prática ambivalente, pois porta aspectos de emancipação e dominação, influenciados, respectivamente, pela macrotendência da "democratização" e da "tecnologização" do discurso.

A democratização pode ser definida pela redução das desigualdades e assimetrias dos direitos, das obrigações e do acesso a tipos de discurso de prestígio para indivíduos considerados de menor poder 10. Essa situação se reproduz no caso do aconselhamento, quando se estabelece uma relação de empatia entre usuário e equipe de saúde e existe abertura para informar e explicar terminologias e temas referentes às DST/ HIV/AIDS.

No pólo oposto à democratização, cabe ressaltar o aspecto do aconselhamento como parte de uma engenharia denominada por Fairclough de "tecnologização". Assimetrias entre equipe de saúde e usuários permanecem quando o aconselhamento se configura como instrumento de ação estratégica que classifica, generaliza e normatiza. Para o autor ${ }^{10}$, as tecnologias de poder trabalhadas por Foucault são formas de tecnologização do discurso encontradas nas práticas de entrevista, ensino, publicidade e aconselhamento.

Foucault 11,12,13 apresenta a disciplina e a confissão como as principais tecnologias de poder, organizadas por procedimentos que se ordenam e se configuram através do sistema de poder-saber e que atuam como mecanismos de controle sobre a vida das pessoas. Para o autor, o sistema disciplinar inclui operações que relacionam atos, desempenhos e comportamentos como mecanismos de comparação, diferenciação e homogeneização de princípios a serem seguidos 13 . O sistema da confissão funciona como técnica de subjetivação, utilizada para trazer o interior das pessoas para dentro de um domínio de saber, estabelecido por um poder ${ }^{12}$. Os métodos da escuta clínica intervêm de forma terapêutica e neles existe uma instância que requer a verdade. No caso do aconselhamento, essa "verdade" é considerada necessária para "a reflexão sobre valores, atitudes e condutas, incluindo o planejamento de estratégias de redução de risco" 2 (p. 11).

Dessa forma, o aconselhamento na prevenção do HIV pode ser visto como estratégia de poder disciplinar e de regulação da população. É uma prática que faz uso de mecanismos classificatórios e avaliativos, como no caso do preenchimento da ficha do sistema de informação implantada pelo Ministério da Saúde; é necessário que o usuário participe de um aconselhamento coletivo, antes da realização do teste anti-HIV; realiza-se atendimento individual que se propõe a conhecer as práticas sexuais dos usuários, bem como os riscos atribuídos a seu(ua)s parceiro(a)s 14 .

Em síntese, o aconselhamento é constituído por um conjunto de intervenções que busca interferir nas condutas da vida cotidiana dos sujeitos. Isso aponta para uma relação dialógica entre usuários e profissionais do serviço e sinaliza a existência de um jogo entre necessidades democraticamente contempladas e modos tecnológicos de agir.

Pesquisas sobre o aconselhamento em serviços de testagem e unidades básicas de saúde sugeriram a necessidade da realização de investigações com enfoque na percepção dos usuários sobre essa prática 3,5,8,9,15. Este artigo analisa os sentidos atribuídos por usuários de um CTA na prevenção do HIV, tendo como principal referencial teórico o processo de democratização dos discursos contextualizado por Fairclough 10 e as tecnologias de poder disciplinar e confissão trabalhadas por Foucault 12,13.

Constitui parte do resultado de uma pesquisa que investigou, além dos sentidos atribuídos ao aconselhamento, o conhecimento prévio, as razões da procura, expectativas, demandas e necessidades dos usuários em relação ao serviço 16.

\section{Metodologia}

Foi realizada pesquisa qualitativa, de caráter exploratório, com orientação analítico-descritiva. $\mathrm{O}$ trabalho foi desenvolvido em duas etapas, no período de novembro de 2005 a março de 2006. A primeira etapa ocorreu no momento de chegada do usuário ao serviço, antecedendo ao aconselhamento pré-teste. A segunda foi ao término do aconselhamento pós-teste, ou seja, após a entrega do resultado do exame aos mesmos usuários entrevistados anteriormente. Este artigo apresenta e discute os resultados relativos à segunda etapa, embora inclua algumas informações referentes à primeira.

\section{Campo de estudo}

A investigação foi desenvolvida em um CTA localizado próximo à região central de uma das cidades com maior número de casos de AIDS do Estado de Minas Gerais, Brasil. É um serviço de referência, inserido no Sistema Único de Saú- 
de (SUS), que atende a uma média de trezentos usuários por mês. Responde à demanda espontânea da população e de encaminhamentos de serviços públicos e privados em saúde, além de outros, como de organizações não-governamentais (ONG) .

$\mathrm{O}$ atendimento inicia-se com a condução dos usuários para a sala de aconselhamento coletivo, usualmente denominada sala de palestra. Posteriormente, eles se dirigem ao local de coleta de sangue e, finalmente, são agendados num intervalo de aproximadamente 15 dias, para o aconselhamento individual pós-teste com entrega do resultado do exame.

Embora não exista um tempo padronizado de duração do aconselhamento pré-teste coletivo, ele costuma variar de 60 a 90 minutos e o pósteste individual de 20 a 30 minutos, conforme características da clientela e do próprio profissional aconselhador. A equipe de aconselhadores estava composta, na época, por seis psicólogos e dois enfermeiros.

\section{Sujeitos do estudo}

Foram selecionados 32 indivíduos com primeiro atendimento em um CTA, maiores de 18 anos, exceto grávidas, devido à possibilidade de demanda relacionada exclusivamente à gravidez. A seleção foi de apenas um entrevistado por turno, segundo ordem de chegada. O número de 32 participantes visava uma coleta contínua, sistemática e diversificada, com entrevistas realizadas com quatro usuários diferentes para cada um dos oito aconselhadores.

\section{Instrumento}

Para a coleta das informações, utilizou-se a técnica de entrevista aberta em profundidade, realizada ao término do aconselhamento individual pós-teste. A partir das questões referentes à expectativa do usuário no momento de chegada ao serviço, abordada na primeira parte do estudo 16 , buscou-se investigar a expectativa comparada pós-atendimento. Posteriormente, pesquisou-se a vivência no aconselhamento pré- e pós-teste, com o fim de se delinear os sentidos atribuídos pelos sujeitos da pesquisa ao aconselhamento realizado. O roteiro de entrevista foi composto das seguintes perguntas: pensando no que você esperava quando chegou aqui, como considera que foi sua experiência?; em sua opinião, como foi ter participado do aconselhamento coletivo?; e hoje, como foi? (referindo-se ao aconselhamento individual); fale mais um pouco sobre a experiência de ter passado por esse serviço. Para a caracterização dos entrevistados por sexo, idade, estado civil e escolaridade, utilizou-se a ficha do Sistema de Informação dos Centros de Testagem e Aconselhamento (SI-CTA), implantada pelo Ministério da Saúde.

A entrevista foi realizada por um único pesquisador, em sala reservada, no próprio local do estudo. Um estudo piloto permitiu a validação do instrumento. Utilizou-se o recurso de gravação. O mesmo pesquisador transcreveu na íntegra o material coletado. As falas dos entrevistados foram identificadas por nomes fictícios para a garantia do anonimato e acrescidas da idade e escolaridade por anos de estudo (a.e.) para se caracterizar o discurso analisado. O estudo foi aprovado pelos comitês de ética em pesquisa da Escola Nacional de Saúde Pública Sergio Arouca da Fundação Oswaldo Cruz e da prefeitura ligada ao CTA investigado.

\section{Organização e análise do material}

A análise foi realizada por uma adaptação do método de análise de conteúdo privilegiando-se a modalidade temática. O processo foi dividido em seis passos, conforme apresentação de AttrideStirling 17. O primeiro deles foi a "familiarização com o texto" e tomada de conhecimento do que as informações estavam dizendo. O segundo passo foi a "identificação de uma estrutura temática", com sucessivas leituras do texto e realização da codificação inicial dos temas. No passo seguinte foi feita a "aplicação desta estrutura aos dados" (indexação ou codificação), que significa a aplicação da estrutura temática ao material coletado, reajustes e realização da codificação inicial. No quarto passo ocorreu a "identificação de tema com casos (Charting)” ou codificação axial. Os temas foram identificados com os casos e organizados de forma a se visualizarem suas correlações. O próximo passo foi o de "mapeamento e interpretação - busca de associações, padrões, conexões e explicações nos dados". O trabalho foi realizado em nível de codificação axial, verificando-se as relações entre os temas e fazendose referência a outras teorias e correlações com outros contextos. O sexto e último passo foi o de "explicação dos dados".

As informações foram processadas pelo programa NUD*IST (QSR International Pty. Ltd., Melbourne, Austrália; http://www.qsrinternatio nal.com) para facilitar o manuseio de um grande número de temas e categorias e auxiliar no cruzamento de alguns deles. Para isso, foram utilizadas estratégias de interseção, associação, congruência e divergência, que favoreceram o aprofundamento da análise.

Após codificação dos temas por expectativa comparada (desde a chegada do usuário ao servi- 
ço até o pós-atendimento), dividiu-se o relato dos entrevistados em dois grandes grupos relacionados à vivência e aos núcleos de sentidos atribuídos ao aconselhamento pré e pós-teste. Foram extraídas as seguintes categorias: prescritivo/ normativo; informativo/esclarecedor; acolhedor/ tranqüilizador; informal/interativo; experiência forte; mal necessário; receptor/protagonista.

\section{Resultado e discussão}

Este estudo contou com a participação de 32 entrevistados com idade entre 18 e 65 anos. As faixas etárias predominantes foram de 25 a 34 anos (34\%) e de 35 a 44 anos (28\%). Os $38 \%$ restantes tinham de 18 a 24 anos (16\%), 45 a 49 anos (13\%) e finalmente, 55 a 65 anos (9\%).

A maioria (53\%) era do sexo masculino e de solteiros. Os separados corresponderam a $25 \%$ e os casados a $22 \%$. O nível de escolaridade dominante variou de oito a 11 anos de estudo (41\%), seguido igualmente com $25 \%$ para os de quatro a sete anos e 12 ou mais; $6 \%$ tinham de um a três anos de estudo e $3 \%$ não informaram.

Quanto ao resultado do exame anti-HIV, 30 usuários obtiveram resultado negativo e dois obtiveram resultado positivo. Nenhum participante informou ser usuário de drogas injetáveis (UDI). A procura pelo serviço esteve comumente relacionada à rede de amigos e encaminhamentos de bancos de sangue 16. A história de mais de um evento de relação sexual desprotegida foi ao mesmo tempo registrada em grande parte dos relatos. Esses achados foram semelhantes aos encontrados em outros estudos 4,8,18.

A expectativa inicial por um atendimento precário, associado à idéia de que o SUS expõe os usuários a filas, burocracia e demora foi reconsiderada diante da agilidade do atendimento, da presteza do diagnóstico e especialidade dos profissionais: "Foi rápido. Muito bom. Que tem, muitas pessoas que ficam cismada né? Porque é gratuito, pensa que o serviço não é de qualidade (...) ficar na fila, mas aqui não, foi pontual" (Sasso, 43 anos, 8-11a.e.).

Expectativas positivas relacionadas à possibilidade de esclarecimento do diagnóstico, de acolhimento, de tratamento e de acompanhamento foram contempladas pelo atendimento, principalmente nas situações de soropositividade: “... a segurança que cês passam pra gente! O carinho, aquela compreensão, orientação né? Porque a doença é uma carência, ainda mais quando se trata de uma coisa dessa. Com quem eu vou conversar, quem vai me ajudar, quem vai me fortalecer? (...) Mas, depois se eu precisar cês vão tá sempre aqui?" (Zânia, 59 anos, 4-7a.e.).
A espera por informação, esclarecimento e orientação foi do mesmo modo confirmada. Esses aspectos foram enfatizados, sobretudo no aconselhamento pré-teste coletivo, que foi considerado como valioso pelo seu caráter "informativo, respeitoso, esclarecedor e acolhedor". Usuários relataram que tiveram informações sobre as formas de transmissão do vírus, sobre o uso do preservativo feminino e sobre outras doenças sexualmente transmissíveis (DST). Comentaram, ainda, que até o momento do pré-teste desconheciam a possibilidade de transmissão do vírus via sexo oral, bem como a "diferença entre HIV e AIDS”. Esses resultados vão ao encontro de pesquisas sobre o aconselhamento em serviços de testagem, fazendo-se referência ao caráter informativo, a clareza da linguagem, a receptividade e o acolhimento $3,4,8,19,20$. A mudança de opinião quanto à visão inicial de um atendimento precário associado ao SUS foi também registrada nesses estudos.

A apropriação de termos técnicos, adquirida pelo acesso à informação e referenciada por Fairclough 10 como uma tendência democratizante, aparece nesse contexto como uma oportunidade de conhecimento de temas específicos da área, que podem auxiliar o usuário na prevenção do HIV/AIDS. A utilização do conceito de janela imunológica, bem como a diferenciação entre estar infectado e estar doente, sinaliza o entendimento da relação entre exposição, risco, possibilidade de tratamento e prevenção: "Então vamos supor, eu tô falando aqui que tá tudo negativo, mais daqui a três meses eu posso tá positivo ué, por causa da janela imunológica" (Tadeu, 34 anos, 8-11a.e.).

$\mathrm{O}$ uso de um recurso ilustrativo durante o aconselhamento pré-teste, retratando o relacionamento sexual que se inicia com um casal e se estende a outras pessoas, também propiciou aos usuários um processo de reflexão e de (re)conhecimento da noção de vulnerabilidade. O desenho realizado pelo aconselhador permitiu que os participantes se vissem como parte integrante de uma rede de contatos que nunca haviam percebido, como observado nesta fala: “ $A h$ ! O que ficou mesmo é essa ilustração dessa rede de relacionamentos. (...) O exemplo que ela deu na palestra foi mais ou menos o da minha vida. Eu nunca parei pra pensar. (...) É uma coisa invisivel, mas ela existe né? É uma rede. E pensar que a gente é um nó ali que tem um monte de coisas ligada à gente né? Isso foi o que mais impressionou" (Desirré, 42 anos, 12 ou mais a.e.).

O período de espera do resultado, entre a participação no pré-teste e o retorno do usuário ao serviço, também foi ressaltado como um espaço vital para que pensassem sobre o que 
haviam vivenciado e para que avaliassem suas possíveis situações de risco e condições de vulnerabilidade: "Eu saí daqui aquele dia com uma outra cabeça, uma nova perspectiva de vida, com um aprendizado muito grande. Isso me fez assim refletir bastante das coisas que eu tava fazendo. (...) Mudar minha maneira de pensar" (Gabriel, 24 anos, 8-11a.e.).

Tanto o aconselhamento pós-teste individual como o atendimento coletivo foram apreciados pelos aspectos esclarecedores e tranqüilizadores. Se o pós-teste foi visto por alguns usuários como um atendimento íntimo, com possibilidade de introdução de novos temas não abordados no aconselhamento coletivo, por outros, foi considerado uma repetição de conteúdos trabalhados no pré-teste. Foi também entendido como o cumprimento de um protocolo para a entrega do resultado do exame e repasse de medidas normativas para a redução do risco ao HIV, através do uso do preservativo: "Ah, a maioria das coisas que eles disseram foi da palestra. E a respeito do sexo oral, que era melhor prevenir né?" (Suzi, 38 anos, 4-7a.e.).

Embora alguns usuários tenham feito menção a este atendimento como uma oportunidade de diálogo, a maioria deles apresentou um posicionamento passivo frente ao discurso do aconselhador, mesmo nos casos em que o sujeito duvidou da orientação recebida: "Para usar camisinha em todas as relações mesmo com a própria esposa. Bom, eu fiquei um pouco assim, tenho que fazer isso mesmo? Se é assim que as pessoas estão orientando então vou fazer isso, a partir de agora. Vou passar a usar, claro" (Chico, 40 anos, 8-11a.e.).

Provavelmente essa passividade esteja associada à construção de autoridade e competência explícita atribuída ao aconselhador enquanto detentor do saber. Nessas condições o usuário ocupa uma posição de receptor da informação. Apesar de o aconselhamento se configurar como uma prática democrática e menos hierárquica, não se pode, na visão de Fairclough 10, desconsiderar a presença de lutas contraditórias, que implicam a preservação de hegemonias focalizadas nas relações, especialmente na relação médicopaciente.

Foram raras as situações em que os usuários entenderam que eles próprios seriam os protagonistas da decisão, construção e manutenção de uma proposta alternativa de prevenção ao HIV. Este posicionamento ativo foi evidenciado em falas que demonstraram reflexão e autoavaliação sobre condições de vulnerabilidade e viabilidade da mudança: “A gente tá assim num relacionamento legal. (...) se o dela der negativo e eu negativo num vai justificar usar camisinha entendeu? (...) eu também não quero ficar com nóia de tá com ela e usa camisinha porque eu não confio. Se eu começar a criar essa nóia eu num vô nem fazer sexo com ela mais. (...) No dia que o fulano [aconselhador] me deu tanta informação, que eu fiquei com dúvida e eu não consegui ter relação com ela. Então assim não quero ter esse grilo entendeu?" (Renato, 36 anos, 12 ou mais a.e.).

As falas dos usuários considerando o atendimento restrito ao risco e à entrega do resultado foram conjugadas a considerações sobre uma abordagem exclusivamente pedagógica; de pouca profundidade; limitada ao aspecto informativo-prescritivo; e pouco definida quanto a seu objetivo, principalmente entre os indivíduos soronegativos: "Isso que é bacana na questão da dimensão do trabalho. O que que eu faço com o negativo e o que que eu faço com o positivo? (...) Diferenciar agora. Se eu tivesse recebido meu exame e fosse negativo (...) eu estaria com a sensação de imunidade, que é extremamente perigosa. Pronto pra recomeçar a minha roda de aventuras [risos] (...) Então se o resultado é negativo o trabalho tem que ser mais burilado, né? O positivo não (...) o que tem de fazer com ele agora é levantar realmente algumas proteções (...). Tem que fazer essa reflexão, se num fizer uma reflexão né! [risos]. Mas isso seria uma outra concepção de atendimento do serviço público" (Otávio, 35 anos, 12 ou mais a.e.).

Nos casos de resultado negativo, os usuários tendem a se sentir protegidos, desconsiderando, assim, as situações de exposição que os conduziram ao serviço. Isso pode levá-los a transitar em novos sistemas de exposição, com a falsa sensação de imunidade, ou contribuir para uma busca repetitiva na realização de novos exames. Nesse caso, a necessidade de repetição de exames num curto espaço de tempo poderia ser entendida como uma falha no atendimento do CTA, diante do seu caráter tipicamente preventivo e que deve privilegiar um plano de ação diante do sistema de vulnerabilidade do sujeito.

De forma conjunta, o aconselhamento pré e pós-teste foi visto como uma experiência forte, congregando sentimentos de tensão, medo, culpa e arrependimento: "Isso pra mim foi uma experiência forte (...). Não, eu não queria ter passado por isso, num precisa nem ter dúvida disso" (Renato, 36 anos, 12 ou mais a.e.).

Sob esse aspecto, o aconselhamento pareceu repercutir ou reforçar no usuário um discurso preventivo centrado no medo, nas boas e más condutas.

"Depois da palestra, (...) falei não [batendo a mão na mesa] a partir de hoje vai ser assim, assim, assim e assim. Isso aqui não pode, isso pode, entendeu? (...) As coisas que eu passei, do susto que eu tomei" (Liza, 26 anos, 8-11 a.e.). 
Estudos revelam, no entanto, que o medo não surge como um bom aliado nos processos que envolvem mudanças de atitude, na medida em que pode gerar pânico, rejeição dos fatos, passividade e/ou resignação diante da impossibilidade de mudanças em determinadas condições ou momentos da vida 21,22,23,24,25. Do mesmo modo o sistema normativo pode funcionar como um efeito corretivo, de gratificação e sanção, capaz de enfraquecer ou confundir o usuário em seu papel de protagonista de sua saúde ou levá-lo a uma reação contrária à adoção de práticas mais seguras 13,22.

Alguns relatos expressaram uma situação de exposição e constrangimento. Considerando-se que parte das afirmações referidas ao constrangimento têm por trás o medo e a angústia da própria realização e do resultado do exame, chamou a atenção a forma diferenciada como esse sentimento foi revelado no momento de chegada ao serviço, durante o aconselhamento coletivo e no individual.

O acanhamento na chegada do usuário ao CTA esteve basicamente relacionado à construção social que uma pessoa tem ao procurar esse tipo de serviço, ou seja, o medo de ser reconhecido e estigmatizado 15. A espera pelo início do atendimento na sala reservada para o aconselhamento coletivo foi traduzida como constrangedora. Tal sentimento foi, no entanto, eliminado diante da informalidade no aconselhamento coletivo, da naturalidade com que os questionamentos e relatos foram tratados, possibilitando aos olhos dos usuários uma oportunidade de compartilhar experiências: "A liberdade que o grupo criou entre si né? Que o fulano [aconselhador] expôs a gente na palestra. (...) a liberdade de perguntar e até desse rapaz falar da situação que ele vive com o namorado! Então pra mim, foi essa parte que me marcou" (Priscila, 21 anos, 12 ou mais a.e.).

Durante o aconselhamento individual, o constrangimento foi referente ao próprio formato do atendimento. Segundo percepção dos entrevistados e como demonstrado em outras pesquisas $3,21,26$, o serviço privilegiou o preenchimento de uma ficha, com perguntas previamente definidas e em muitos casos não condizentes com o contexto do aconselhamento e/ou história de vida do usuário. Esse momento foi apontado em alguns casos como invasivo e ofensivo como pode ser observado: "As perguntas que foram feitas e que eu tive que responder! Ninguém nunca tinha feito isso comigo. Isso se eu já fiquei com homem? Um amigo há pouco tempo me contou que a ex-namorada perguntou para ele se ele tinha transado com outro homem. Ele fico muito bravo, muito irritado. Naquele momento quis dar um bo- fetada nela, mas, me controlei. E fez essa pergunta da maneira que perguntou também aqui, igual. É uma ofensa viu? Mas, (...) eu respondi, não tem problema não" (Chico, 40 anos, 8-11 a.e.).

Numa leitura Foucaultiana 12 pode-se dizer que essa etapa do aconselhamento está associada em grau significativo à técnica da confissão, quando as pessoas são chamadas a falar sobre si, erigindo um contexto de verdade. Em nome da verdade/confissão, indispensável ao diagnóstico e à eficácia das intervenções terapêuticas, há uma relação que não pode ser negligenciada e que ocorre de forma assimétrica. De um lado está a instância que requer a confissão e de outro aquele que confessa e que se vê pressionado. O último mergulha em si mesmo, enquanto ao primeiro é dada a condição para "julgar, punir, perdoar, consolar, reconciliar" 12.

Em uma outra perspectiva, Giddens 27 ressalta aspectos conversacionais de práticas sociais que se configuram como espaços em que o eu pode se constituir enquanto projeto reflexivo/ interrogativo. Para o autor, há, nas sociedades modernas, uma tendência à abertura e espaço para a constituição de auto-identidades denominadas reflexividade institucional, que não têm correlação com um processo confessional ou necessariamente controlador, como revelado por Foucault 12. Dentro desse enfoque menos mecânico e controlador, o aconselhamento aparece fortemente associado a um processo de autoidentidade e de natureza reflexiva do corpo, que proporciona um ímpeto básico às mudanças 27 .

A significação do aconselhamento como um "mal necessário" revela sua ambivalência: "É um constrangimento né? E afasta, essa coisa de ouvir a palestra esse tempo todo, afasta muita gente daqui. (...) mas, eu acho que é importante, eu não sei como né? Como que teria que ser pra não afastar, porque é necessário, é um mal necessário [risos]" (Meire, 31 anos, 12 ou mais a.e.).

Essa ambigüidade, porém, não foi interpretada pelos entrevistados como algo problemático ou conflitivo. Ao contrário, os usuários tiveram um trânsito fácil entre os aspectos democráticos e coercitivos. A dificuldade pareceu mais relacionada à construção de um modelo de interação que não apenas privilegie a informalidade e a simetria nas relações, mas que tenha como foco a participação do usuário como sujeito atuante e interessado em suas condições de saúde.

Nesse contexto o aconselhamento pós-teste revelou limitações importantes no que se refere à construção conjunta, entre profissional e usuário, de um plano de redução de riscos. O discurso do aconselhamento tem como eixo central o favorecimento da autonomia e da autogestão dos sujeitos para a prevenção e promoção da saúde. 
Sua política de prevenção parte do pressuposto de que, através da informação e do diálogo, seja possível proporcionar à pessoa condições para que avalie seus próprios riscos e maneiras de enfrentar seus problemas relacionados às DST/ HIV/AIDS

O espaço do pós-teste poderia ser melhor aproveitado se na relação com o usuário fossem propostas questões que tivessem conexões com sua história de vida e suas condições de vulnerabilidade. É importante que esse atendimento não fique limitado à realização de perguntas padrões que aos olhos dos usuários ficam desconectadas e restritas a um mesmo modelo de prevenção, comumente focalizado no risco/cuidado com o sexo oral e uso do preservativo. Essa relação necessita, portanto, ser construída de forma menos hierárquica, na medida em que necessita de uma aproximação com as demandas e necessidades dos sujeitos.

\section{Considerações finais}

Este estudo revelou uma prática de aconselhamento paradoxal, visto que aos olhos dos usuários ela acolhe e gera tensão, dialoga e normatiza, amedronta e motiva, permite reflexão e paralisa. Do mesmo modo, foi possível identificar posicionamentos diferenciados dos entrevistados ao fazerem referência à necessidade ou perspectiva de mudança de suas condições de vulnerabilidade. De um lado, os relatos sinalizaram para alguns posicionamentos participativos em relação à tomada de decisão e construção de uma alternativa preventiva. De outro lado e de forma mais marcante, identificou-se a presença de um discurso passivo e pouco reflexivo, limitado ao aspecto informativo e prescritivo das medidas de prevenção ao HIV. Nesses casos, o medo, a culpa e o julgamento do que é certo e errado foram a tônica capaz de influenciá-los quanto à necessidade de um sexo seguro.

Nesse contexto, deve-se pensar a complexidade do aconselhamento na prevenção do HIV como uma grande engrenagem, em que diferentes discursos podem existir dentro de uma mesma estratégia conjugando modos informais e regulatórios, liberadores e disciplinares. Isso significa que a norma e o diálogo podem servir, ao mesmo tempo, como orientação e auxílio para um processo de auto-identidade e de mudanças, em que os sujeitos podem resistir, interferir e negociar com os variados tipos de discurso materializados na interação aconselhador-usuário.

Para além da capacidade informativa, confirmadamente atribuída ao aconselhamento, o desafio é a constituição de uma assistência efetivamente mais democrática, com enfoque na vulnerabilidade e um atendimento direcionado à mobilização de uma atitude participativa e autônoma dos usuários. Para isso, será necessário responder de forma mais efetiva às demandas e necessidades das pessoas que buscam o centro de testagem. O atendimento humanizado, com grande possibilidade de escuta, gerador de processos reflexivos e um maior incremento do trabalho preventivo entre os indivíduos soronegativos, pode ser um caminho para a melhoria de resultados na prevenção do HIV/AIDS.

\section{Resumo}

O objetivo do artigo foi analisar os sentidos atribuídos pelos usuários de um centro de testagem ao aconselhamento na prevenção do HIV. Tomou-se como principal referencial teórico o processo de democratização dos discursos contextualizado por Fairclough e as tecnologias de poder disciplinar e de confissão trabalhadas por Foucault. A pesquisa foi realizada de novembro de 2005 a março de 2006, em um Centro de Testagem e Aconselhamento (CTA) de Minas Gerais, Brasil. Participaram do estudo 32 indivíduos. Utilizou-se a técnica de entrevista em profundidade e uma adaptação do método de análise de conteúdo privilegiando-se a mo- dalidade temática. A significação do aconselhamento como "mal necessário" revelou uma prática ambivalente, de abordagem democrática e coercitiva. Essa ambigüidade, porém, não surgiu como algo problemático. A dificuldade esteve relacionada à construção de modelos de interação que não apenas privilegiem a simetria nas relações, mas que tenham como foco a participação do usuário como protagonista na prevenção do HIV.

Aconselhamento; Síndrome de Imunodeficiência Adquirida; Educação em Saúde 


\section{Colaboradoras}

V. Souza participou na concepção da pesquisa, trabalho de campo, análise, redação do artigo e revisão após considerações do corpo editorial da revista. D. Czeresnia participou na concepção do estudo, discussão dos resultados, revisão crítica do texto e da versão final após correções. C. Natividade participou na concepção, discussão dos resultados, redação preliminar e revisão do texto após considerações do corpo editorial da revista.

\section{Agradecimentos}

Aos profissionais e usuários do serviço de saúde pesquisado. Ao aluno Reginaldo Rodrigues dos Santos pela cooperação na pesquisa. À doutoranda Ana Cristina Borges de Oliveira pela leitura crítica do artigo. Aos pesquisadores: Marcelo Rasga Moreira, Suely Ferreira Deslandes, Corinne Davis Rodrigues e Kathie Njaine pelas valiosas colaborações.

\section{Referências}

1. Kamb ML, Fishbein M, Douglas Jr. JM, Rhodes F, Rogers J, Bolan G, et al. Efficacy of risk-reduction counseling to prevent human immunodeficiency virus and sexually transmitted diseases: a randomized controlled trial. Project RESPECT Study Group. JAMA 1998; 280:1161-7.

2. Coordenação Nacional de DST e AIDS, Secretaria de Políticas de Saúde, Ministério da Saúde. Aconselhamento em DST, HIV e AIDS: diretrizes e procedimentos básicos. 3a Ed. Brasília: Ministério da Saúde; 1999.

3. Filgueiras SL, Deslandes SF. Avaliação das ações de aconselhamento: análise de uma perspectiva de prevenção centrada na pessoa. Cad Saúde Pública 1999; 15 Suppl 2:S121-31.

4. Ferreira MPS, Silva CMFP, Gomes MCF, Silva SMB. Testagem sorológica para HIV e a importância dos Centros de Testagem e Aconselhamento (CTA): resultados de uma pesquisa no município do Rio de Janeiro. Ciênc Saúde Coletiva 2001; 6:481-90.

5. Cappi DRS, Jesus JG, Nichiata LYI, Takahashi RF. Atuação de estudantes de enfermagem em um centro de orientação e aconselhamento (COAS) para HIV: relato de experiência. Rev Latinoam Enferm 2001; 9:66-72.
6. Goldani MZ, Giugliani ERJ, Scanlon T, Rosa H, Castilhos K, Feldens L, et al. Aconselhamento e testagem voluntária para o HIV durante a assistência pré-natal no Brasil. Rev Saúde Pública 2003; 37:552-8.

7. Programa Nacional de DST/AIDS, Secretaria deVigilância em Saúde, Ministério da Saúde. Priorizar a inserção do diagnóstico do HIV e aconselhamento na rotina da rede básica no âmbito do processo de descentralização. http://dtr2004.saude.gov.br/ dab/caadab/documentos/segunda\%20mostra/ aconselhamento_dst_hiv_atencao_basicadenise_ serafim.pdf (acessado em 20/Abr/2007).

8. Minayo MCS, Souza ER, Assis SG, Cruz Neto O, Deslandes SF, Silva CFP. Avaliação dos Centros de Orientação e Apoio Sorológico/CTA/Coas da Região Nordeste do Brasil. Cad Saúde Pública 1999; 15:355-67.

9. Monteiro S. Qual prevenção? AIDS, sexualidade e gênero em uma favela carioca. Rio de Janeiro: Editora Fiocruz; 2002.

10. Fairclough N. Discurso e mudança social. Brasília: Editora UnB; 2001.

11. Foucault M. A arqueologia do saber. 7ạ Ed. Rio de Janeiro: Forense Universitária; 2005. 
12. Foucault M. A história da sexualidade. I: a vontade de saber. 16a Ed. Rio de Janeiro: Edições Graal; 2005.

13. Foucault M. Vigiar e punir: nascimento da prisão. 31a Ed. Petrópolis: Editora Vozes; 2006.

14. Souza V, Czeresnia D. Considerações sobre os discursos do aconselhamento nos centros de testagem anti-HIV. Interface Comun Saúde Educ 2007; 11:531-48.

15. Araújo CLF. A prática de aconselhamento em DST/ AIDS e a integralidade. In: Pinheiro R, Mattos RA, organizadores. Construção da integralidade: cotidiano, saberes e práticas em saúde. Rio de Janeiro: Instituto de Medicina Social, Universidade do Estado do Rio de Janeiro/ABRASCO; 2003. p. 145-68.

16. Souza V. Discurso do aconselhamento na prevenção do HIV e o olhar dos usuários do serviço [Tese de Doutorado]. Rio de Janeiro: Escola Nacional de Saúde Pública Sergio Arouca, Fundação Oswaldo Cruz; 2007.

17. Attride-Stirling J. Thematic networks: an analytic tool for qualitative research. Qual Res 2001; 1:385405

18. Souza SMB. Perfil epidemiológico da clientela dos centros de testagem e aconselhamento para o HIV em Goiás - Brasil. Rev Eletrônica Enferm 2002; $4: 49$.

19. Araújo CLF. Aconselhadores, acolhedores,....: a prática de aconselhamento em DST/AIDS em um CTA do Estado do Rio de Janeiro [Tese de Doutorado]. Rio de Janeiro: Instituto de Medicina Social, Universidade do Estado do Rio de Janeiro; 2003.

20. Secretaria de Projetos Especiais de Saúde, Coordenação Nacional de DST/AIDS, Ministério da Saúde. Aconselhamento: um desafio para a prática em Saúde. Brasília: Ministério da Saúde; 1997.
21. Mann J, Tarantola JM, Netter TW, organizadores. A AIDS no mundo. Rio de Janeiro: Editora RelumeDumará; 1993.

22. Fernandes JCL. Práticas educativas para a prevenção do HIV/AIDS: aspectos conceituais. Cad Saúde Pública 1994; 10:171-80.

23. Blanco JA, Eiros JM, Gastrodeza J, Aguado A, Ortizde-Lejarazu R, Rodrigues-Torres A. La infección VIH/SIDA en la prensa española desde 1986 hasta 1992. In: Nájera-Morrondo R, Conzáles-Lahoz J, editores. Avances en SIDA 1995: editoriales y revisiones de la publicación oficial interdisciplinar del SIDA. Madrid: IDEPSA; 1996. p. 82-6.

24. Domingues RC. Considerações psicossociais sobre a testagem anti-HIV. In: Morando L, Guimarães R, organizadores. AIDS: olhares plurais; ensaios esparsos sobre a epidemia de HIV/AIDS. Belo Horizonte: Coordenadoria Estadual de DST/AIDS de Minas Gerais; 1998. p. 53-83.

25. Queiroz EMM, Nogueira PHQ. Possibilidade e limite do trabalho em educação sexual como estratégia de prevenção à AIDS e à discriminação na rede municipal de educação da Prefeitura Municipal de Belo Horizonte, iniciando o debate. In: Morando L, Guimarães R, organizadores. AIDS: olhares plurais; ensaios esparsos sobre a epidemia de HIV/AIDS. Belo Horizonte: Coordenadoria Estadual de DST/ AIDS de Minas Gerais; 1998. p. 31-9.

26. Costa MAO. Aconselhamento para o teste antiHIV: o olhar de profissionais de unidades básicas de saúde de Belo Horizonte [Dissertação de Mestrado]. Belo Horizonte: Escola de Enfermagem, Universidade Federal de Minas Gerais; 2004.

27. Giddens A. Modernidade e identidade. Rio de Janeiro: Jorge Zahar Editor; 2002.

Recebido em 28/Dez/2006

Versão final reapresentada em 18/Out/2007 Aprovado em 30/Out/2007 